\title{
Dynamic Simulation and Optimization of a Urea Granulation Circuit
}

\author{
Ivana Cotabarren $^{\S *}$, Diego Bertín ${ }^{\S}$, Juliana Piña ${ }^{\S}$, Verónica Bucalá ${ }^{\S}$, José Romagnoli ${ }^{\dagger}$ \\ ${ }^{\dagger}$ Chemical Engineering, Louisiana State University, Cain Department of Chemical \\ Engineering, South Stadium Road, Baton Rouge, LA 70803, USA. \\ ${ }^{\S}$ Department of Chemical Engineering - PLAPIQUI - UNS - CONICET \\ Camino La Carrindanga Km. 7, (8000) Bahía Blanca, Argentina \\ e-mail: icotabarren@plapiqui.edu.ar
}

\begin{abstract}
A dynamic flowsheet for a complete urea granulation circuit is presented in this work. This flowsheet is based on previous validated models against industrial data for the crusher and screen and on a new model for the granulation unit. All three units are integrated under the gPROMS Molder Builder Environment, which allows having a powerful tool for the simulation and optimization steps. A sensitivity analysis is performed to evaluate the influence the different operating variables on the product and recycle streams. Finally, an optimization is carried out to determine the values of the manipulated variables that maximize production under specification.
\end{abstract}

\section{Introduction}

Granulation is a key particle size enlargement process widely used in the pharmaceutical, food, mining and fertilizer industries. This operation converts fine particles and/or atomizable liquids into granular material with desired properties. The granulation process is considered as one of the most significant advances in the fertilizers industry, providing products with high resistance and low tendency to caking and lump formation. Urea granulation is a complex operation that cannot be carried out in a single device; it is rather achieved by a combination of process units with specific functions constituting the granulation circuit (Figure 1, Korotkiy et al., 2004). The main unit is the granulator (commonly a fluidized bed), where small urea particles known as seeds (generally product out of specification) are continuously introduced and sprayed with a concentrated solution of the fertilizer. The seeds grow through deposition of the fertilizer solution droplets onto the solids surface, followed by water evaporation and urea solidification (Bertin et al., 2007). The granules that leave the enlargement size unit are classified in double-deck screens into product, oversize and undersize streams. The product is transported to storage facilities, while the oversize fraction is fed to crushers for size reduction. The crushed oversize particles are then combined with the undersize granules and returned to the granulator as seeds (Cotabarren et al., 2008). 


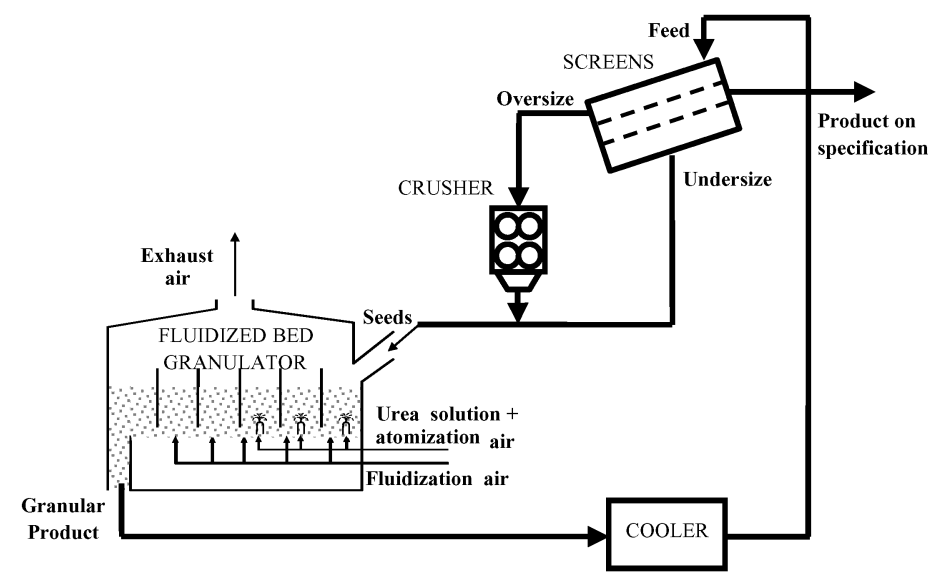

Figure 1. Typical urea granulation circuit.

Generally, in fertilizer granulation plants only a relatively small fraction of the material leaving the granulator is in the specified product size range; therefore important recycle ratios are common. The characteristics of the recycle, which are the consequence of what happened previously in the granulator, influence what will happen later on in that unit. In extreme cases, the cycling surging and drifting of particles coupled with the large dead time can result in plant shut down or permanent variations in the plant capacity and product quality. To minimize these problems it is necessary to have a fundamental understanding of the effects of the recycling of material on the behavior of the granulation circuit (Adetayo et al., 1995, Heinrich et al., 2003).

In view of this and the relatively high current installed world urea capacity as well as its forecasted expansion (from $136 \mathrm{Mt}$ in 2008 up to $192 \mathrm{Mt}$ in 2011), the dynamic modeling and simulation to optimize the urea granulation circuits operation will play an important role in this fertilizer economy (Heffer and Prud'Homme, 2008). In the present work, previous validated models against industrial data for the crusher (Cotabarren et al., 2008a) and screen units (Cotabarren et al., 2008c) are integrated with a granulator model (that assumes the growth process as the main mechanism in the fluidized bed granulation) into a dynamic circuit flowsheet by means of an equation-oriented modeling system (gPROMS Model Builder Environment). The complete circuit dynamic model is then used to carry out sensitivity analyses by studying the effect of different operating variables on the particle size distributions (PSDs) and mass flowrates of the product and recycle streams. Once the critical variables are identified, the gPROMS optimization tools are used to maximize the plant production maintaining the marketable product granulometry.

\section{Crushers, screens and granulator models}

Bearing in mind the importance of the simulation tools to predict the granulation circuit performance, which cannot be done intuitively, reliable models for all the circuit units are required. The double-roll crusher model was presented in a previous contribution (Cotabarren et al., 2008a) and based on the model of Austin et al. (1980). The crusher model parameters were fitted using available plant data. The screen model was founded 
on the one developed by Karra (1979), which represents a non-ideal classification operation by determining the oversize partition coefficients for each size interval. The parameters needed to calculate the cut size diameter and the partition coefficients were also adjusted by using experimental data collected from industrial granular urea screens (Cotabarren et al., 2008c). The urea fluidized-bed granulator is basically a bed of solids fluidized by air, fed continuously with small urea particles (seeds) and a urea concentrated liquid solution ( $96 \mathrm{wt} \%$ ) that is sprayed from the bottom of the unit. The bubbling nature of the fluidized bed, which is responsible for the strong solids mixing, promotes the repeatedly circulation of the granules through the spraying zone. The granules grow through the deposition of tiny liquid droplets on the seed material, followed by cooling and evaporation of the water content of the droplets, which cause the solidification of the urea present in the solution. To increase the residence time of the granules, the industrial units possess several growth chambers (where the urea concentrated solution is sprayed) in series. Subsequently, fluidized bed cooling compartments are arranged to meet specific requirements for further processing of the granules (Bertin, et al., 2007). In this work, the granulator was represented by three growing chambers followed by three cooling compartments. The outlet granulator particle size distributions were predicted by using population balances for all the chambers and assuming that each chamber operated as a continuous perfectly mixed bed, the mass holdup within each compartment was constant and the main growth mechanism was layering (elutriation, agglomeration, breakage, attrition and nucleation are negligible). Details about this model and its numerical solution can be found elsewhere (Cotabarren et al., 2008b). The screen and crusher were assumed to operate in pseudo-steady state as the kinetics of these processes in comparison with the granulation one were fast and did not have a large effect on the system dynamics (Wildeboer, 1998). The granulator was modeled as a dynamic process. All the models were integrated in the gPROMS Model Builder Environment in order to perform dynamic simulations and optimizations.

\section{3. gPROMS Implementation}

gPROMs is a multipurpose tool mainly used to build and validate process models, for steady-state and dynamic simulation and steady-state and dynamic optimizations (gPROMS Documentation, 2008). The units were integrated in the gPROMS Model Builder Environment in order to perform dynamic simulations and optimizations. A complete plant flowsheet, flexible for future control analyses, was desired. For this purpose gPROMs has special basic libraries that allow constructing several flowsheets. However, the granulation plant was implemented by building specific user model libraries for each of the plant units, using the provided flowsheeting tools. The sensitivity analysis was performed with the go:RUN application. The go:RUN allows the user to execute a pre-existing model from within another software (e.g. Microsoft Excel). By executing the developed model from Microsoft Excel, the go:RUN provides a simplified and interactive user interface (go:RUN User Guide). The optimization was performed by means of the optimization tools presented in the gPROMs Model Builder environment. An objective function was set to be maximized with a point optimization routine. Controls and constrained variables were then defined. 


\section{Results}

\subsection{Sensitivity analysis}

This study was performed by running various dynamic gPROMS simulations of the integrated granulation circuit. The aim was to determine the influence of different operating variables on the circuit performance. It is of special interest to evaluate the impact on the plant capacity (product flow rate), product quality, recycle fraction and recycle quality. The quality evolution of both streams was followed through the product and recycle SGN (Size Guide Number) as well as the product UI (Uniformity Index). The manipulated variables chosen for the sensitivity analysis were the urea melt flowrate $\left(m_{\text {melt }}\right)$, top and bottom decks screen apertures $\left(h_{T}\right.$ and $\left.h_{B}\right)$ and upper and lower crusher gaps $\left(G A P_{U}\right.$ and $\left.G A P_{L}\right)$. The dynamic evolution of all the variables of the granulation circuit was analyzed. Due to the lack of space only one example is included. Figure 2 shows the product $\mathrm{SGN}$ and mass flowrate as a function of time when a step disturbance in $G A P_{L}$ is assayed.
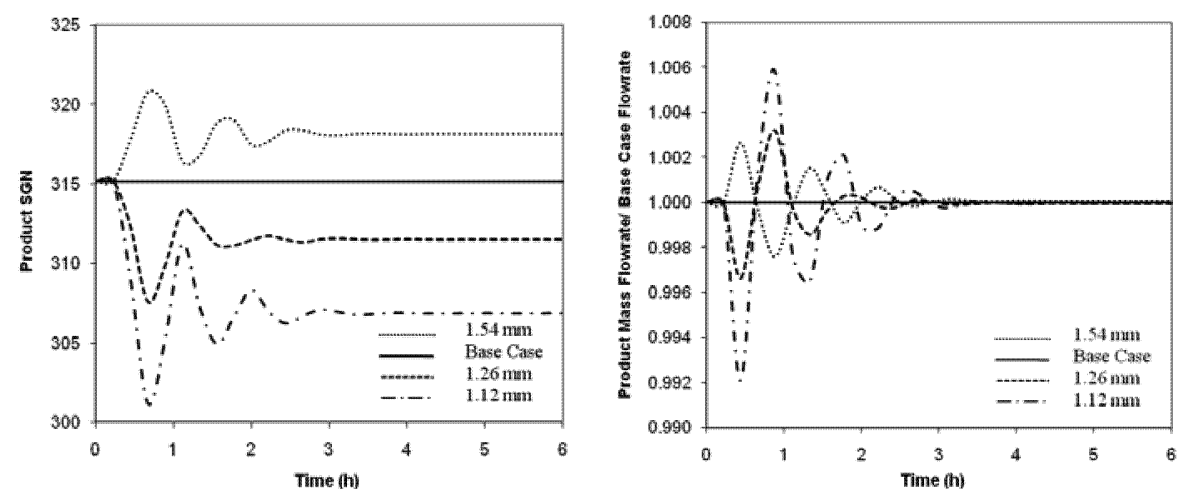

Figure 2: Effect of changing the lower crusher gap

The product and recycle variables were quite insensitive to changes on the crusher upper gap (Figure 3). Even though the PSD of the upper pair of rolls outlet stream changes, the gap of the lower pair of rolls (constant for this analysis) allowed almost reestablishing the final granulometry of the stream. On the other hand, the lower crusher had an important influence on the product granulometry and flow and on the recycle ratio. As the lower gap increased the SGN of the product and the recycle also increased, the recycle ratio decreased and the product UI remained almost constant. This variable may be adjusted to modify the median of the product. As it can be concluded from Figure 3, the screen top and bottom deck apertures were the variables that most strongly affect the performance of the granulation circuit. Although these variables can not be changed under operation, the study of their effect on the circuit performance can be useful to define the appropriate screen meshes or to predict the effect of the apertures blinding. When the bottom screen aperture was increased, the product SGN and UI raised and the recycle ratio increased. The increase of the top deck aperture allowed coarsening the product but the PSD became broader (lower UI) since the size difference between the two apertures increased. 
As expected, the product mass flowrate was directly affected by the amount of urea melt added to the system. When the plant capacity was increased and any other variable was modified, the product exhibited a lower SGN and the PSD became wider. It is important to note that the circuit migrated to a different final steady state. However, for the disturbances analyzed, the quality of the product did not change significantly with the melt disturbance.
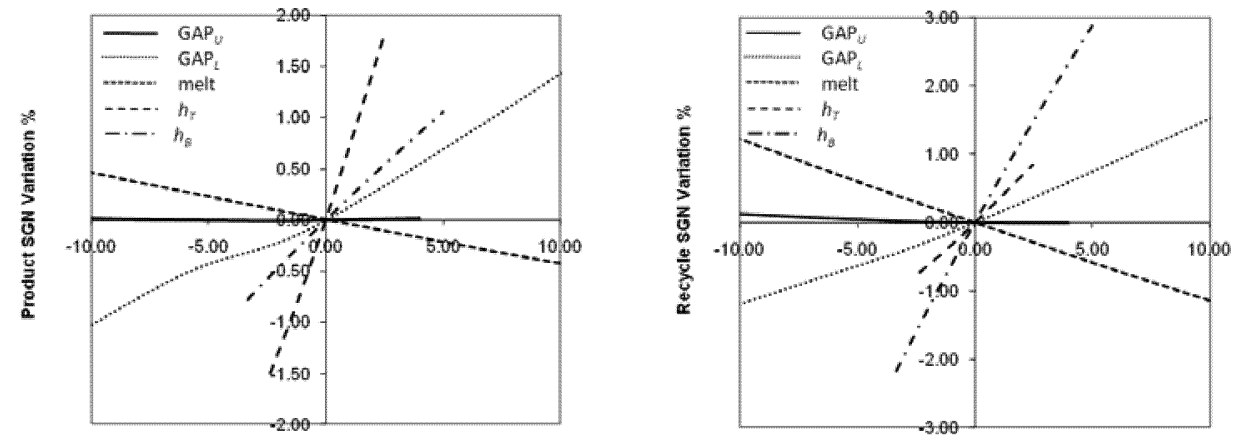

Manipulated Variable Variation \%

Manipulated Variable Variation \%
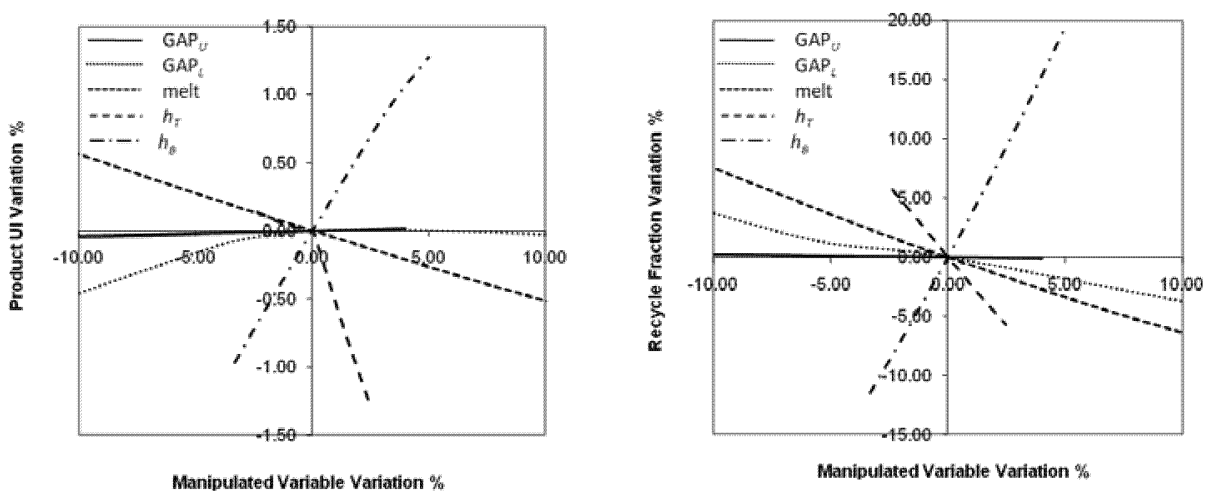

Manipulated Variable Variation \%

Figure 3: Percentage of change in the product and recycle variables against the percentage of change in the manipulated variables.

\subsection{Optimization}

Two optimization problems were analyzed: 1) maximize the plant product flowrate by manipulating the urea melt sprayed in each chamber and both crusher gaps, and 2) maximize the product flowrate, optimizing both deck apertures, the urea melt and the crusher gaps. Both optimizations were performed considering the following constraints: the production cannot be higher than $20 \%$ of the plant basic capacity, the product SGN must be within the 300-320 range and the UI between 50 and 60 . The optimization results are shown in Table 1. As expected from the sensitivity analysis, the deck apertures were modified in a lower percentage than the crusher gaps. If it is desired to increase the plant capacity, the results indicate that either the crusher gaps or the deck aperture have to be modified to obtain the product with a marketable granulometry. 


\begin{tabular}{cccc}
\hline & Base Case & Optimization 1 & Optimization 2 \\
\hline Objective Function & & & \\
Product flowrate (\%) & $100 \%$ & $119 \%$ & $119 \%$ \\
Optimization Variables & & & \\
$\mathrm{GAP}_{\mathrm{U}}(\mathrm{mm})$ & 2.50 & 2.36 & 2.02 \\
$\mathrm{GAP}_{\mathrm{L}}(\mathrm{mm})$ & 1.40 & 1.60 & 1.67 \\
$\left.\mathrm{Urea}_{\mathrm{melt}} \%\right)$ & $100 \%$ & $119 \%$ & $119 \%$ \\
$\mathrm{~h}_{\mathrm{T}}(\mathrm{mm})$ & 4.15 & - & 4.17 \\
$\mathrm{~h}_{\mathrm{B}}(\mathrm{mm})$ & 3.00 & - & 2.72 \\
Constrains & & & \\
Product SGN (mm x 100) & 315.18 & 319.40 & 317.44 \\
Product UI (mm x 100) & 53.19 & 52.62 & 51.05 \\
\hline
\end{tabular}

\section{Conclusions}

Even though the assayed disturbances affect the system variables; the sensitivity analysis indicated that the circuit has certain capacity of self-control. The present study revealed that the effect of the variables on the circuit operation verifies the following order of importance: $h_{T}>h_{B}>G A P_{L}>m_{\text {melt }}>G A P_{U}$. This result indicates that the screen apertures blinding over time may affect the product quality significantly, being particularly important for the bottom deck since it handles a lot of fines. This work illustrates that the granulation circuit simulator is a valuable tool to select the appropriate variables values to meet the desired production requirements.

\section{References}

Adetayo, A.A., Litster, J.D., Cameron I.T., 1995, Computers Chem. Eng. 19, 383-393. Austin L.G., Van Orden D.R., Perez J.W., 1980, Int. J. Mineral Processing 6, 321-336 Bertin, D.E., Mazza, G.D., Piña, J., Bucalá, V., 2007, Industrial and Engineering Chemistry Research 46, 7667-7676.

Cotabarren, I., Schulz, P.G., Bucalá, V., Piña, J., 2008a, Powder Technology 183 (2), 224-230.

Cotabarren, I. Bertin, D.E., Bucalá, V., Piña, J. 2008b. RITeQ - I Interdisciplinary Meeting on Technology and Chemical Processes, Córdoba, Argentina, Abstract RQ-34. Cotabarren, I., Rossit, J., Bucalá, V., Piña, J., 2008c. Particle Technology Forum, 2008 AIChE Annual National Meeting, Philadelphia, USA, Abstract 189f.

go:RUN User Guide, version 2.3.1, 2004, Process System Enterprise Ltd. London, UK. gPROMs Documentation, Release 3.1.4, 2008, Process Systems Enterprise Ltd., London, U K.

Heffer, P., Prud'Homme, M, 2008, Turk J Agric For, 32, 159-164.

Heinrich, S., Peglow, M., Mörl, L., 2003, Powder Technology 130, 154-161.

Karra, V. K., 1979, CIM Bull 72 (804), 167-171.

Korotkiy I., Brazgovka A., Kremers G., 1976, 10 ${ }^{\text {th }}$ Stamicarbon Urea Symp., 2004. Wildeboer, W.J., Masters Thesis, Delft University of Technology, 1998. 